\title{
Proactive interference and cuing effects in short-term cued recall: Does foil context matter?
}

\author{
WINSTON D. GOH and HUIQIN TAN \\ National University of Singapore, Singapore
}

\begin{abstract}
Tehan and Humphreys's $(1995,1996)$ short-term cued recall paradigm showed that recall in shortterm memory is cue driven. In critical trials, the participants studied two blocks of four words each and were required to forget the first block while remembering the second block. A foil in the first block (e.g., orange) was related to a target (e.g., carrot) in the second block. Proactive interference (PI) was evident when a retrieval cue was used that subsumed the foil and the target (e.g., type ofjuice), but not when a cue was used that subsumed only the target (e.g., type of vegetable). Four experiments were performed to examine the extent to which contextual organization in the foil block would enhance or diminish the foil's efficacy in creating PI. A novel condition was included in which the words in the foil block were studied in a phonologically related context but the target was cued semantically, and vice versa with a semantic context and phonological cue. There were no differences in recall accuracy between conditions with and without contextual organization, but reliable increases in foil intrusions were observed when contextual organization was present. Contextual organization enhanced the foil, rather than diminished it, but the strengthened foil generated PI only when the cue subsumed the foil and the target and had no effect when the cue subsumed only the target. The results are consistent with a cue-driven retrieval interpretation of short-term recall.
\end{abstract}

A recent review of contemporary research in short-term memory (STM) has argued for a reconceptualization of short-term recall as a cue-driven process (Nairne, 2002b). This is contrasted with the traditional view of STM, dubbed the standard model by Nairne (2002b), in which recall is driven primarily by rehearsal processes countering the effects of decay over time (e.g., Baddeley, 2000; Baddeley \& Hitch, 1974). Recasting short-term recall as a cue-driven process brings the conceptualization of STM closer to what is known about retrieval and forgetting processes in long-term memory (LTM), where interference, and not decay (cf. McGeoch, 1932), is seen as the primary cause of forgetting.

The bulk of the evidence against the standard model has come from studies demonstrating LTM contributions in STM tasks. For example, such attributes of words as frequency (e.g., Hulme et al., 1997; Roodenrys \& Quinlan, 2000), lexicality (e.g., Hulme, Maughan, \& Brown, 1991), phonological neighborhoods (e.g., Goh \& Pisoni, 2003; Roodenrys, Hulme, Lethbridge, Hinton, \& Nimmo, 2002), phonotactics (e.g., Gathercole, Frankish, Picker-

This work was supported, in part, by Research Support Scheme C107-000-222-091 and Research Grant R-107-000-048-112, awarded to the first author. We thank Michael Humphreys, Gerald Tehan, and an anonymous reviewer for constructive criticism of an earlier version of the manuscript. Correspondence concerning this article should be addressed to W. D. Goh, Department of Psychology, National University of Singapore, Singapore 117570 (e-mail: psygohw@nus.edu.sg).

Note-This article was accepted by the previous editorial team, when Colin M. MacLeod was Editor. ing, \& Peaker, 1999), and semantics (e.g., Bourassa \& Besner, 1994; Walker \& Hulme, 1999) influence immediate serial recall performance. It has been suggested that these attributes can be used as effective retrieval cues in a redintegration or clean-up process to reconstruct STM traces from LTM in the event that a direct readout from STM cannot be achieved due to trace degradation (e.g., Nairne, 1990; Schweickert, 1993).

The efficacy of retrieval cues in short-term recall can also be inferred from studies in which the organization of words within and across lists was manipulated. Poirier and Saint-Aubin (1995) showed that when words within a list are derived from the same conceptual class (e.g., musical instruments) and the conceptual class changes across lists, immediate recall is better, in comparison with a condition in which each word is from a different conceptual class. This pattern of results has been replicated with rhyme categories (e.g., Fallon, Groves, \& Tehan, 1999), which is an interesting finding, given that phonological similarity typically leads to poorer recall (Conrad \& Hull, 1964). However, both categorical and phonological similarity have also been shown to enhance performance in order reconstruction tasks (e.g., Nairne \& Kelley, 1999; Nairne \& Neumann, 1993), particularly when similarity is maintained within lists but not across lists. Taken together, these findings strongly suggest that when an organizational principle is present in the context of a word list, participants are able to make use of this organizational factor as an effective retrieval cue for short-term recall, presumably by restricting the potential memory search set and responses to words that are consistent with the cue or organizational principle. 
The hypothesis that short-term recall is dependent on the efficacy of retrieval cues was directly tested by Tehan and Humphreys $(1995,1996)$, using an STM cued recall task. This task involved trials in which participants were presented either two blocks of four words or a single block of four words. In the single-block trials, the participants were required to recall the words in that block, but in the two-block trials, the participants were required to forget the first block and recall only words from the second block. The purpose of the single-block trials was to ensure attention to the first block. Figure 1 shows a schematic of the sequence of events in the critical two-block trials. In these trials, the effect of interest was whether the words from the first block would influence recall of the words in the second block. This was manipulated by having a target word in the to-be-remembered second block (e.g., carrot) that shared conceptual attributes with a foil word in the to-be-forgotten first block (e.g., orange). A further manipulation involved the nature of the retrieval cue that was presented to the participants. In one condition, the cue (e.g., type of juice) subsumed both the foil and the target, whereas in another condition, the cue (e.g., type of vegetable) subsumed only the target. Retrieval of carrot was impaired in the former condition, but not in the latter, demonstrating that whether proactive interference (PI) affected recall depended on the nature of the cue used at retrieval. Tehan and Humphreys $(1995,1996)$ also demonstrated similar effects, using rhyme categories with this paradigm. These findings are consistent with those of previous research using the release from PI paradigm (Wickens, 1970), which demonstrated that susceptibility to PI is diminished when cues that uniquely discriminated and specified the words in the current trial were utilized (see, e.g., Dillon \& Bittner, 1975; Gardiner, Craik, \& Birtwistle, 1972).

Thus, the critical factor for determining the efficacy of a retrieval cue appears to depend on the extent to which the cue can provide diagnostic information about the occurrence of the target (Nairne, 2002a). One can think of cues in terms of their usefulness. For example, if one was asked to search for a particular individual and was told that this person was a boy in school uniform, this informa-

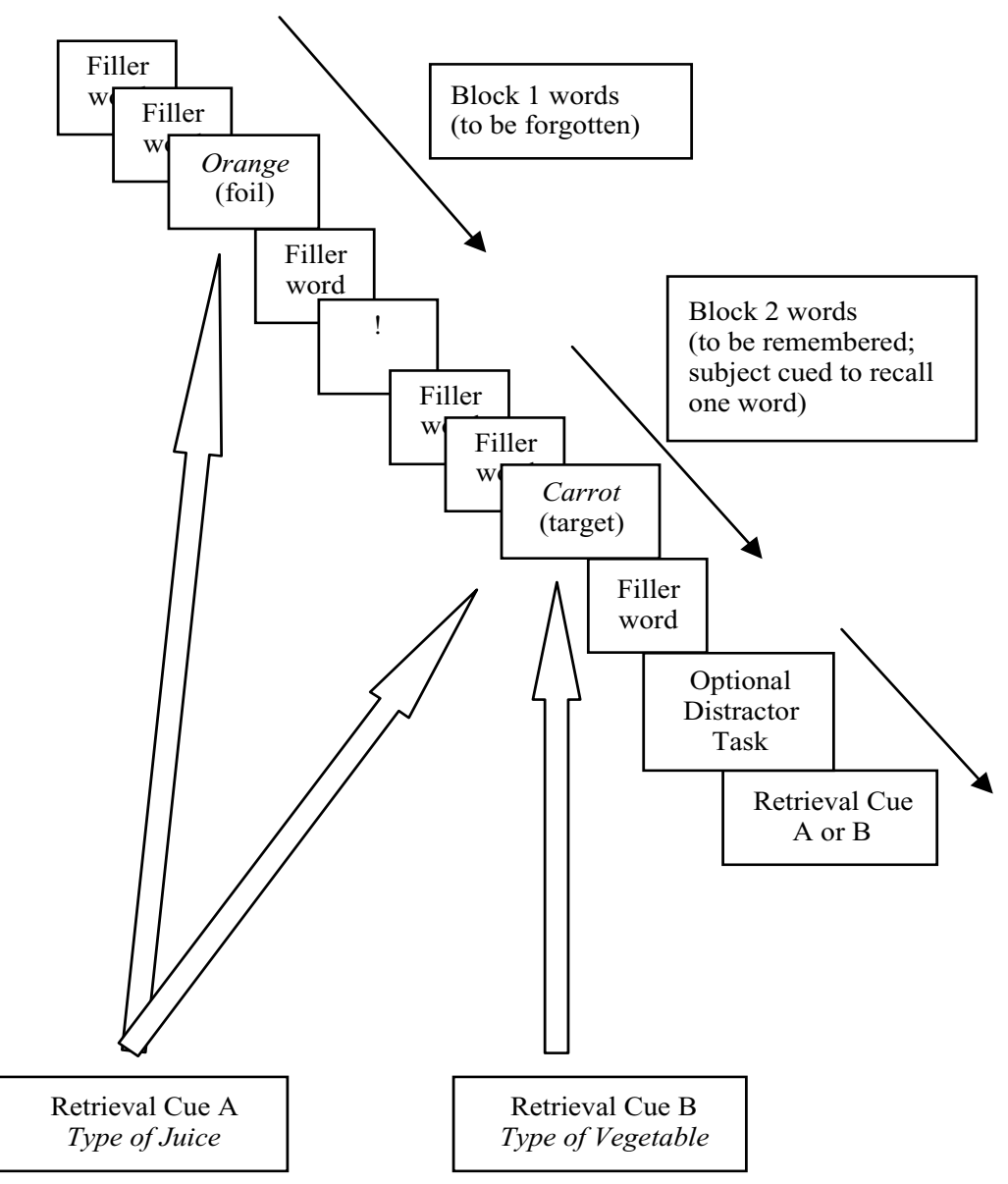

Figure 1. Schematic of a critical two-block trial, with large arrows indicating associative links between the foil, target, and retrieval cues. Proactive interference between orange and carrot is likely when type of juice is used as a retrieval cue, but not when type of vegetable is used as a retrieval cue. 
tion would most probably be very helpful for identifying such a person in a room full of adults. However, the same cue would practically provide no distinctive information about the target in the setting of a school cafeteria. In other words, the efficacy of a cue would be highest if it uniquely matched the target and little else.

Tehan and Humphreys (1998) extended their earlier findings with this paradigm by demonstrating that PI can also be increased when a target (e.g., cat) is accompanied by an unrelated filler word (e.g., $\log$ ) in the second block that rhymes with the foil (e.g., dog) in the first block. PI also increased when the unrelated fillers in the second block contained phonemes of the foil (e.g., dart, mop, or fig). Such findings suggest that fillers that share phonemic features with the foil may result in increased activation of the foil, so that participants will be more likely to incorrectly recall the foil, instead of the target, when the retrieval cue subsumes both the foil and the target. Manipulating the properties of the fillers in the target context appears to strengthen the foil. This suggests that the context in which the target appears may also be important in determining susceptibility to PI and the efficacy of retrieval cues in the short-term cued recall task.

An interesting follow-up to this study would be to determine whether foil context, rather than the target context, will have any effects on PI. Placing the contextual items in the foil block may result in effects that are different from those found by Tehan and Humphreys (1998), because the foil is now being studied together with the contextual items and the task is to forget and inhibit this set of items. In the earlier study, the contextual items were in the target block, and the task was to remember an item from this block, as determined by the cue. Hence, any features of words within the target block ought to receive less inhibition.

One possibility is that foil context may diminish, rather than enhance, susceptibility to PI. There are two possible rationales for this prediction. One comes from the earlier observation that when words within lists were organized according to a rhyme or semantic dimension (Fallon et al., 1999; Nairne \& Kelley, 1999; Nairne \& Neumann, 1993; Poirier \& Saint-Aubin, 1995), recall performance was superior, in comparison with word lists lacking such an organization. As has been noted, item similarity may provide a categorical cue that aids retrieval. In turn, the particular dimension that organizes the words within the list may enhance the saliency of that specific attribute of the words and may diminish other attributes. To give a concrete example, a word list comprising loo, shoe, flu, and zoo may raise the salience of the rhyme dimension, and the semantic attributes of each word may be relatively less salient.

A second rationale for predicting diminished PI effects is based on differential effects found when extralist or intralist cues are used. For example, recall for targets that have many associates is worse than that for targets with fewer associates when cues that were not previously studied are used, but this effect disappears when cues previously studied with the targets are used (e.g., Nelson, Bennett, Gee, Schreiber, \& McKinney, 1993). The argument is that with intralist cuing, only the link between the studied cue-target pairing is activated and all other irrelevant associates are inhibited (Nelson et al., 1993; see also Nelson, McKinney, Gee, \& Janczura, 1998). If item similarity can automatically provide a categorical cue, one could argue that this cue is akin to an intralist cue, in the sense that it was generated during the study of the words in the foil block. If the foil context emphasizes the rhyme dimension, the link between the rhyme and the words will be activated, and links with other attributes, such as semantic properties, may be inhibited. Consequently, it will be harder to cue the foil with an extralist cue that subsumes a different dimension, and this, therefore, will lead to fewer problems in retrieving the target in the second block. It should be noted that focusing on the rhyme dimension does not necessarily mean that semantics will not be encoded, since Nelson et al. (1993; see also Nelson, Walling, \& McEvoy, 1979) reported that target set size effects did not disappear when rhyme pairs were studied (e.g., seep-weep) that were subsequently cued semantically (e.g., cry), although overall recall was worse, in comparison with a control condition.

In the context of Tehan and Humphreys's $(1995,1996)$ cued recall task, suppose that shoe is a foil for the target boot and the retrieval cues are either type of footwear (subsumes shoe and boot) or part of a car (subsumes only boot). A foil block with rhyming words may diminish PI effects and raise the semantic retrieval cue's efficacy even when it subsumes both the target and the foil. The influence of a potentially interfering foil may be reduced by focusing on an incompatible dimension (the rhyme in this example) or by the inhibition of other features and properties that are incompatible with the studied foil context.

Of course, another possibility is that the foil will be strengthened, as was found by Tehan and Humphreys (1998), if fillers in the foil block share properties with the foil. The logic is that these shared features result in an increase in foil activation that, consequently, causes greater interference with the target when a retrieval cue that subsumes both is given. Hence, the likelihood of the foil's being retrieved is enhanced. A replication of Tehan and Humphreys's (1998) findings would support their view that all the features of studied words in memory will be automatically activated and will be simultaneously available for retrieval, despite the fact that this block of words had to be forgotten or inhibited.

Both the prediction of PI enhancement and the predictions of diminished PI suggest that cue-target diagnosticity depends also on the nature of the fillers in the foil block. However, a final possibility is that PI effects are not enhanced or diminished under such manipulations, which would suggest that cue-target diagnosticity depends entirely on the dimension that the retrieval cue emphasizes, regardless of other dimensions or contextual information that may organize the words in the foil block.

The proposed manipulations may also shed some light on the extent to which short-term cued recall depends on encoding and retrieval processes. Tehan and Humphreys (1996) rejected the possibility that an encoding explanation could be used to explain their results - that is, that 
the participants encoded the similarity between the targets and the foils, and this resulted in increased PI. Among the reasons for this rejection was that all the items except for the foil and the target were unrelated and inherently multidimensional. Consequently, the participants were unlikely to encode the precise relationship between the foil-target pair within the constraints of the experimental procedure.

We suggest that a strong test of whether encoding processes contribute to recall is to orient participants to a dimension shared by all the words in the foil block that is incompatible with the retrieval cue and examine the effect on the degree of PI observed. If the participants do encode the rhyme category in the foil block and recall does not vary with foil context, PI effects can be unequivocally attributed to retrieval processes, since such a result would imply that the encoding context does not matter. However, if PI effects vary with foil context, it may suggest that encoding also has some influence on PI effects in cued recall.

\section{EXPERIMENT 1}

Experiment 1 introduced a novel condition, manipulating rhyming and nonrhyming fillers, into the first block in the STM cued recall paradigm described in Tehan and Humphreys $(1995,1996)$. Table 1 depicts the structure of the critical two-block trials. In the control (or nointerference) conditions, all the words except the target were unrelated to the retrieval cue. In the rhyming conditions, all the fillers were semantically unrelated but rhymed with the foil, whereas in the nonrhyming conditions, the fillers were semantically unrelated and did not rhyme with the foil. In the same-category conditions, the retrieval cue subsumed both the foil and the target, whereas in the different-category conditions, the retrieval cue subsumed only the target.

Following the logic of Tehan and Humphreys (1995, 1996), differential recall performance between the sameand the different-category conditions, relative to the relevant control conditions, would indicate the degree of PI effects. The extent to which foils are recalled instead of targets (classified as Block 1 intrusion errors) would also be strong indicators of PI. We expected to replicate Tehan and Humphreys's $(1995,1996)$ findings in the nonrhyming conditions: When a same-category cue subsuming the foil and the target was presented, performance would be impaired; however, no impairment should be evident when the different-category cue subsuming only the target was presented. In the novel rhyming conditions, the extent to which the rhyme category influenced the PI effect could be observed by examining the differences in the degree of $\mathrm{PI}$, relative to the nonrhyming conditions.

\section{Method}

Participants. Forty-four introductory psychology students participated for course credit.

Design and Materials. Sixty monosyllabic foil-target pairs were created by selecting two nonrhyming members from each of 60 unique categories. Forty-five of the pairs were sampled from the Battig and Montague (1969) and McEvoy and Nelson (1982) norms, whereas the rest were created by the authors. Following Tehan and Humphreys (1996), most of the foils were the more dominant instance of the category, whereas the targets were selected so that they could be conceived of as instances of alternative categories. The rhyming fillers of the foils were obtained from the Nelson, McEvoy, and Schreiber (1998) norms and were semantically unrelated to the foil-target pairs and the recall cues. These words are listed in the Appendix, along with the recall cues for the same- and the differentcategory conditions.

The words were randomly divided into six word lists, with each list comprising 10 foil-target pairs and the corresponding rhyming fillers. Seventy nonrhyming fillers were added to each list for use as unrelated fillers. All of these fillers had characteristics similar to those of the critical items - all were monosyllabic, and $97 \%$ were nouns - but were not semantically related to the critical items within each list. Each list of 120 words, therefore, comprised 10 foils, 10 targets, 30 rhyming fillers, and 70 nonrhyming fillers. The lists were equated for average word frequency, on the basis of the Kučera and Francis (1967) counts. The average log frequency for the six lists ranged from 1.95 to 2.01 (overall $M=2.00, S D=0.60$ ); a oneway between-subjects ANOVA run across lists was not significant $(F<1)$. Another 120 fillers were selected for the 30 one-block trials of four words each. Ten of these trials comprised fillers that rhymed within list, whereas 20 included nonrhyming fillers. This $1: 2$ ratio is identical to the 2:4 ratio of the number of conditions in the twoblock trials that included rhyming and nonrhyming fillers in the first

Table 1 Structure of Critical Two-Block Trials in Experiment 1

\begin{tabular}{llccc}
\hline & & Control & Nonrhyming & Rhyming \\
\hline Block 1 (foil block) & Filler & $\mathrm{x}$ & $\mathrm{x}$ & loo \\
& Foil/filler & $\mathrm{x}$ & shoe & shoe \\
& Filler & $\mathrm{x}$ & $\mathrm{x}$ & flu \\
& Filler & $\mathrm{x}$ & $\mathrm{x}$ & $\mathrm{zoo}$ \\
& Block separator & $!$ & $!$ & ! \\
Block 2 (target block) & Filler & $\mathrm{x}$ & $\mathrm{x}$ & $\mathrm{x}$ \\
& Target & boot & boot & boot \\
& Filler & $\mathrm{x}$ & $\mathrm{x}$ & $\mathrm{x}$ \\
& Filler & $\mathrm{x}$ & $\mathrm{x}$ & $\mathrm{x}$ \\
& Distractor task & & & \\
& Recall cue & & & \\
\hline
\end{tabular}

Note-In the same-category conditions, type of footwear was presented as the recall cue, which subsumed both the foil and the target. In the different-category conditions, part of a car was presented as the recall cue, which subsumed only the target: $\mathrm{x}$ represents an unrelated filler word. The distractor task was a math verification problem. 
block. This was to ensure that the participants could not predict oneand two-block trials on the basis of list organization.

The experiment was run completely within subjects. To counterbalance lists across conditions, a $6 \times 6$ balanced Latin square was used to rotate the six lists among the six experimental conditions, which were formed by crossing the three rhyming conditions (control, nonrhyming, or rhyming) with the two retrieval cue category conditions (same or different). The program controlling the experiment selected the appropriate types of fillers and recall cues, depending on the condition each list was assigned to. For each participant, the 30 one-block and 60 two-block trials comprising all six conditions were randomly interspersed throughout the experiment so that the participants would have no prior knowledge and could not anticipate the number of blocks in each trial or the nature of the conditions. Following Tehan and Humphreys (1995, 1996), the foils and targets always appeared in the same serial position within their blocks, with half in the second serial position and half in the third serial position. The first and last serial positions were not used, in order to avoid primacy and recency effects.

Procedure. The participants were told to commit the most recently presented block of four words to memory. Thus, for a twoblock trial, the participants were to memorize the first block, but if a block separator, in the form of an exclamation mark (!), appeared after the first block, the participants were required to forget the words in the first block and memorize only the words in the second block and recall the word indicated by the recall cue. For one-block trials, the recall cue instructed the participants to perform serial recall of all the words. The participants were told to treat all blocks as one-block trials, until they learned otherwise from the appearance of the block separator.

Each trial began with a READY prompt centered on the computer monitor for $2 \mathrm{sec}$. The words were then displayed individually at a rate of one word $/ \mathrm{sec}$. The participants were instructed to silently articulate each word as it was presented. At the end of the trial, a distractor in the form of a math verification task (e.g., "Is $(8 / 2)+$ $6=11$ ?") was presented. The participants responded yes or no, using preassigned keys on the keyboard. Once a response had been detected, the recall cue was displayed. For one-block trials, the cue was "Recall all words"; for two-block trials, the cue relevant to the experimental condition was displayed. The participants wrote their responses on prepared answer sheets and initiated the next trial by pressing the enter key. The participants were allowed a short break at the end of every 30 trials. A practice block of 2 one-block trials and 3 two-block trials, using words that were not part of the experimental trials, was conducted at the beginning of the session to familiarize the participants with the task and procedure.

\section{Results}

One participant did not complete the experiment, and another failed to follow instructions and performed serial, instead of cued, recall for all the conditions. These participants were not included in the analyses. Serial recall performance in the one-block trials was useful in serving as an accuracy check to ensure that the participants were, indeed, paying attention to the first block. This was obviously crucial for any PI effect to materialize, because if the participants ignored the first block, the foil would naturally have no effect on cued recall. We adopted a criterion of minus two $S D$ s from the average serial recall rate in the one-block trials $(M=.68, S D=.18)$, to screen out the participants who were not paying attention to the first block of words. One participant failed to meet this criterion. Thus, the subsequent analyses include the scores from 41 participants. We also examined the proportion of accurate responses in the distractor task and found it to be very high $(M=.95, S D=.06)$, indicating that the participants were conscientiously verifying the math equations.

Recall performance is summarized in Table 2. Errors were classified as Block 1 intrusions (recall of words from the first block that were in the same serial position as the target), omissions (no response), or item errors (other words).

Recall analyses. A 2 (cue: same category or different category) $\times 3$ (filler: control, nonrhyming, or rhyming) repeated measures ANOVA on recall rates revealed a significant interaction $\left[F(2,80)=4.77, M S_{\mathrm{e}}=0.01, p<\right.$ $.05]$. The source of the interaction is a significant simple main effect of filler with same-category cue $[F(2,80)=$ $\left.3.32, M S_{\mathrm{e}}=0.02, p<.05\right]$, but not with differentcategory cue $\left[F(2,80)=1.12, M S_{\mathrm{e}}=0.01\right.$, n.s. $]$. The latter result indicates that there were no differences in recall rates regardless of the nature of the foil block when the retrieval cue subsumed only the target, which replicated the results from Tehan and Humphreys (1995, 1996): When the retrieval cue subsumed only the target, no PI effect was observed.

Within the same-category cue conditions, three additional comparisons were used to determine whether recall probability depended on the nature of the fillers in the foil block. The first comparison compared performance in the nonrhyming condition with that in the control condition. This established the presence of a PI effect and replicated the results found in Tehan and Humphreys $(1995,1996)$. The difference was marginally significant $[F(1,40)=$

Table 2

Mean Correct Recall and Error Rates in Experiment 1

\begin{tabular}{|c|c|c|c|c|c|c|c|c|}
\hline \multirow[b]{3}{*}{ Condition } & & & \multicolumn{6}{|c|}{ Type of Error } \\
\hline & \multicolumn{2}{|c|}{ Recall } & \multicolumn{2}{|c|}{$\begin{array}{c}\text { Block 1 } \\
\text { Intrusions }\end{array}$} & \multicolumn{2}{|c|}{ Omissions } & \multicolumn{2}{|c|}{ Item } \\
\hline & $M$ & $S D$ & $M$ & $S D$ & $M$ & $S D$ & $M$ & $S D$ \\
\hline \multicolumn{9}{|l|}{ Same-category retrieval cue } \\
\hline Control (no interference) & .80 & .18 & .00 & .02 & .10 & .15 & .12 & .11 \\
\hline Nonrhyming fillers & .74 & .24 & .06 & .09 & .10 & .15 & .09 & .09 \\
\hline Rhyming fillers & .74 & .20 & .10 & .13 & .06 & .10 & .09 & .09 \\
\hline \multicolumn{9}{|l|}{ Different-category retrieval cue } \\
\hline Control (no interference) & .81 & .17 & .00 & .00 & .10 & .14 & .10 & .13 \\
\hline Nonrhyming fillers & .83 & .17 & .00 & .02 & .08 & .13 & .09 & .10 \\
\hline Rhyming fillers & .85 & .16 & .01 & .03 & .10 & .17 & .08 & .10 \\
\hline
\end{tabular}


4.07, $\left.M S_{\mathrm{e}}=0.02, p=.05\right]$, indicating that the expected PI effect was observed: When the retrieval cue subsumed both the foil and the target, recall was impaired. In the second and third comparisons, performance in the novel rhyming condition was compared with that in the control and nonrhyming conditions, respectively. These were done to determine whether the rhyme context in the foil block would have enhanced or diminished the PI effect. Recall impairment using rhyming fillers was reliable, in comparison with the control condition $[F(1,40)=5.46$, $\left.M S_{\mathrm{e}}=0.01, p<.05\right]$, but there was no reliable difference in the magnitude of the PI effect when rhyming or nonrhyming fillers were used in the foil block $(F<1)$. Therefore, no evidence of an enhancement or attenuation of the PI effect due to rhyming fillers was found in the recall rate measures.

Error analyses. The error analyses were conducted with a 3 (error: Block 1 intrusions, omissions, or item errors) $\times 2$ (cue) $\times 3$ (filler) repeated measures ANOVA. We acknowledge that this may not be entirely appropriate, given that, as was expected, there were very few Block 1 intrusions in the different-category cue conditions and the control condition for the same-category cue. We therefore supplemented the ANOVA results with the relevant nonparametric tests for the critical comparisons. The critical comparison is between the rhyming and the nonrhyming fillers conditions for Block 1 intrusions when same-category cues are used. This comparison is the most critical, since it will indicate whether the novel rhyming filler condition resulted in greater or fewer foil intrusions, in comparison with the interference level in the standard nonrhyming filler condition, and, correspondingly, will give direct evidence for enhanced or diminished PI as a function of contextual organization. This was tested with a Wilcoxon test. Other relevant comparisons include comparing the three filler conditions for omissions and item errors to determine whether there were differential effects due to the nature of the fillers. These were tested with Friedman tests. In the majority of cases, both parametric and nonparametric tests revealed identical results.

The ANOVA revealed a significant three-way interaction $\left[F(4,160)=4.16, M S_{\mathrm{e}}=0.01, p<.01\right]$. Analyses of the error $\times$ filler simple interactions for each cue condition showed that the simple interaction was significant with same-category cue $\left[F(4,160)=8.20, M S_{\mathrm{e}}=0.01\right.$, $p<.001]$, but not with different-category cue $(F<1)$. The latter result indicates that the proportion of errors did not depend on the nature of the fillers when the retrieval cue subsumed only the target and, thus, will not be considered further.

Within the same-category cue conditions, we analyzed the simple main effect of filler for each of the three error types to establish whether the error rates depended on the nature of the fillers, followed by paired $t$ tests, where necessary, to identify specific differences. The simple main effect of filler was significant for both Block 1 intrusions $\left[F(2,80)=15.43, M S_{\mathrm{e}}=0.01, p<.001\right]$ and omissions $\left[F(2,80)=3.43, M S_{\mathrm{e}}=0.01, p<.05\right]$, but not for item errors $\left[F(2,80)=1.02, M S_{\mathrm{e}}=0.01\right.$, n.s. $]$. Specific compari- sons showed that the greatest number of Block 1 intrusions occurred with rhyming fillers, followed by nonrhyming fillers, and the control condition [all $t \mathrm{~s}(40)>2.29, p \mathrm{~s}<$ $.05]$. The Wilcoxon test $(Z=2.22, p<.05)$ confirmed these findings, with 18 participants showing more Block 1 intrusions in the rhyming than in the nonrhyming conditions, 8 with the opposite pattern, and 15 ties. These findings showed that rhyming fillers increased the number of foils incorrectly recalled. For omissions, there were fewer errors in the rhyming condition than in the nonrhyming and control conditions [both $t \mathrm{~s}(40)>2.04, p \mathrm{~s}<.05$ ], with no difference between the latter two $(t<1)$. However, the Friedman test was not significant for omissions or for item errors [both $\chi^{2}(2, N=41)<3.55$, n.s.].

\section{Discussion}

Taken together, the findings can be summarized as follows. In terms of recall accuracy, when the retrieval cue subsumed the foil and the target, target recall was impaired. Whether the foil block included rhyming or nonrhyming fillers did not seem to matter. However, when the degree of Block 1 intrusion errors is considered, having fillers that rhymed with the foil in the first block increased the probability that an incorrect foil response was made, relative to the probability of a foil intrusion when no rhyming fillers were included. These patterns of results are similar to the findings of Tehan and Humphreys (1998), where a rhyme in the second block increased the probability of Block 1 intrusion errors. The present results extend the previous work by demonstrating a similar effect when the rhyming fillers are included in the foil block and support the view that shared features among the fillers strengthen foil activation and cause increased interference for targets. When the cue subsumes the foil and the target, cue-target diagnosticity depends on both the dimension emphasized by the retrieval cue and the context in which the foil is studied. We will defer comment on the implications for encoding and retrieval processes until the General Discussion section.

\section{EXPERIMENT 2A}

Experiment 2A reversed the roles of the semantic and phonological dimensions in the experimental design in order to test the generality of the findings from Experiment 1 . If cue-target diagnosticity depends on both the dimension emphasized by the retrieval cue and the nature of the foil block, we would expect the same pattern of results as that obtained in Experiment 1.

Table 3 depicts the structure of the critical two-block trials. The foil block now comprised words that were all semantically related - for example, crane, duck, stork, or swan - or unrelated. If the target in Block 2 was buck, the retrieval cues were either the rhyme portion that was shared by the foil and the target (e.g., rhymes with luck; subsumes both the foil duck and the target buck) or the onset-nucleus portion of the target (e.g., sounds like the beginning of butt; subsumes only the target buck). Tehan and Humphreys (1995, 1996) used word fragments, such as endings (e.g., _uck) and beginnings (e.g., buc_), as phonological retrieval 
Table 3

Structure of Critical Two-Block Trials in Experiments 2A and 2B

\begin{tabular}{|c|c|c|c|c|}
\hline & & Control & Unrelated & Related \\
\hline \multirow[t]{5}{*}{ Block 1 (foil block) } & Filler & $\mathrm{x}$ & $\mathrm{x}$ & crane \\
\hline & Foil/filler & $\mathrm{x}$ & duck & duck \\
\hline & Filler & $\mathrm{x}$ & $\mathrm{x}$ & stork \\
\hline & Filler & $\mathrm{x}$ & $\mathrm{x}$ & swan \\
\hline & Block separator & $!$ & $!$ & $!$ \\
\hline \multirow[t]{6}{*}{ Block 2 (target block) } & Filler & $\mathrm{x}$ & $\mathrm{x}$ & $\mathrm{x}$ \\
\hline & Target & buck$^{*} / \mathrm{dud}^{\dagger}$ & buck$^{*} / \mathrm{dud}^{\dagger}$ & buck $^{*} / \mathrm{dud}^{\dagger}$ \\
\hline & Filler & $\mathrm{x}$ & $\mathrm{x}$ & $\mathrm{x}$ \\
\hline & Filler & $\mathrm{x}$ & $\mathrm{x}$ & $\mathrm{x}$ \\
\hline & Distractor task & & & \\
\hline & Recall cue & & & \\
\hline
\end{tabular}

Note $-\mathrm{x}$ represents an unrelated filler word. The distractor task was a math verification problem. $\quad{ }^{*}$ For Experiment $2 \mathrm{~A}$, buck was the target. In the rhyme conditions, rhymes with luck was presented as the recall cue, which subsumed both the foil and the target. In the onset conditions, sounds like the beginning of butt was presented as the recall cue, which subsumed only the target. †For Experiment $2 \mathrm{~B}, d u d$ was the target. In the onset conditions, sounds like the beginning of done was presented as the recall cue, which subsumes both the foil and the target. In the rhyme conditions, rhymes with thud was presented as the recall cue, which subsumes only the target.

cues. However, we felt that there was a possibility that participants might, at times, be able to use orthography, rather than phonology, with such cues. Specifically, providing a whole word, rather than fragments, and directing participants to the relevant phonological portion of the word would maximize phonological processing.

We expected to replicate Tehan and Humphreys's $(1995,1996)$ findings in the semantically unrelated conditions: When a rhyme retrieval cue that subsumed both the foil and the target was presented, performance would be impaired; however, no impairment would occur when an onset retrieval cue that subsumed only the target was presented. In the novel related conditions, the extent to which the related category influenced the PI effect could be observed by examining the differences in the degree of PI, relative to the unrelated conditions.

\section{Method}

Participants. Forty introductory psychology students participated for course credit. None had participated in Experiment 1.

Design and Materials. Sixty monosyllabic foil-target pairs were created by selecting two semantically unrelated members from each of 60 unique rhyme categories (Nelson et al., 1998). The taxonomic fillers of 42 foils were obtained from Battig and Montague (1969) and McEvoy and Nelson (1982), with the rest generated by the authors. These fillers did not share rhyme and onset nucleus components with the foil-target pairs and the recall cues. These words are listed in the Appendix, along with the recall cues for the rhyme and onset conditions. As in Experiment 1, the words were randomly divided into six 120 -word lists, with each list comprising 10 foils, 10 targets, 30 taxonomic fillers, and 70 unrelated fillers. As before, the lists were equated for average word frequency $(F<1)$, with the average $\log$ frequency for the six lists ranging from 1.98 to 2.06 (overall $M=2.01, S D=0.68$ ). Another 120 fillers were selected for the 30 one-block trials of 4 words each. Ten of these trials comprised fillers that were taxonomically related within list, and the rest included unrelated fillers. As before, this was to ensure that the participants could not predict one- and two-block trials on the basis of list organization.

The same design and counterbalancing procedures as those in Experiment 1 were used. The unrelated and related conditions in the present experiment were analogous to the nonrhyming and rhyming conditions, respectively, in the previous experiment. The rhyme and onset retrieval cues were analogous to the same-category and different-category retrieval cues, respectively, in Experiment 1.

Procedure. The same procedure as that in Experiment 1 was used. Several examples of what is meant by sounds like the beginning of, using words that were not part of the experimental trials, were presented during the practice session to ensure that the participants understood this retrieval cue.

\section{Results}

The average serial recall rate in the one-block trials was $.69(S D=.20)$. Four participants failed to exceed the criterion of minus two $S D$ s from the mean, and the subsequent analyses included 36 participants. The proportion of accurate responses in the distractor task was very high $(M=.93, S D=.07)$. Recall performance is summarized in the top half of Table 4.

Recall analyses. The ANOVA on recall rates yielded no reliable cue $\times$ filler interaction $\left[F(2,70)=1.65, M S_{\mathrm{e}}=\right.$ 0.03 , n.s.] or main effect of cue $(F<1)$. The main effect of filler was significant $\left[F(2,70)=11.81, M S_{\mathrm{e}}=0.02\right.$, $p<.001]$, with follow-up analyses showing that recall was best in the control condition, followed by the unrelated and then the related conditions [all $t \mathrm{~s}(35)>2.22$, $p \mathrm{~s}<.05]$. We will defer discussion of these results until after the error analyses have been presented.

Error analyses. An error $\times$ cue $\times$ filler interaction was observed $\left[F(4,140)=7.72, M S_{\mathrm{e}}=0.01, p<.001\right]$. As in Experiment 1, the error $\times$ filler simple interaction was significant for rhyme cue $\left[F(4,140)=12.51, M S_{\mathrm{e}}=\right.$ $0.01, p<.001]$, but not for onset cue $(F<1)$. Again, the latter result indicates that the proportion of errors did not depend on the nature of the fillers when the retrieval cue subsumed only the target and, thus, will not be considered further.

Within the rhyme cue conditions, the simple main effect of filler was significant for Block 1 intrusions $[F(2,70)=$ $\left.22.74, M S_{\mathrm{e}}=0.01, p<.001\right]$, but not for omissions 
Table 4

Mean Correct Recall and Error Rates in Experiments 2A and 2B

\begin{tabular}{|c|c|c|c|c|c|c|c|c|}
\hline \multirow[b]{3}{*}{ Condition } & & & \multicolumn{6}{|c|}{ Type of Error } \\
\hline & \multicolumn{2}{|c|}{ Recall } & \multicolumn{2}{|c|}{$\begin{array}{c}\text { Block 1 } \\
\text { Intrusions }\end{array}$} & \multicolumn{2}{|c|}{ Omissions } & \multicolumn{2}{|c|}{ Item } \\
\hline & $M$ & $S D$ & $M$ & $S D$ & $M$ & $S D$ & $M$ & $S D$ \\
\hline \multicolumn{9}{|c|}{ Experiment 2A } \\
\hline \multicolumn{9}{|l|}{ Rhyme retrieval cue } \\
\hline Control (no interference) & .79 & .16 & .01 & .02 & .05 & .07 & .15 & .13 \\
\hline Unrelated fillers & .69 & .23 & .11 & .14 & .04 & .07 & .16 & .13 \\
\hline Related fillers & .68 & .22 & .17 & .17 & .03 & .06 & .11 & .12 \\
\hline \multicolumn{9}{|l|}{ Onset retrieval cue } \\
\hline Control (no interference) & .74 & .19 & .01 & .03 & .04 & .08 & .20 & .15 \\
\hline Unrelated fillers & .73 & .19 & .02 & .04 & .05 & .09 & .21 & .18 \\
\hline Related fillers & .64 & .23 & .03 & .07 & .08 & .13 & .23 & .18 \\
\hline \multicolumn{9}{|c|}{ Experiment 2B } \\
\hline \multicolumn{9}{|l|}{ Onset retrieval cue } \\
\hline Control (no interference) & .66 & .20 & .00 & .00 & .11 & .14 & .23 & .16 \\
\hline Unrelated fillers & .64 & .24 & .10 & .10 & .10 & .16 & .17 & .15 \\
\hline Related fillers & .65 & .21 & .10 & .11 & .08 & .14 & .16 & .12 \\
\hline \multicolumn{9}{|l|}{ Rhyme retrieval cue } \\
\hline Control (no interference) & .81 & .17 & .00 & .02 & .07 & .11 & .12 & .12 \\
\hline Unrelated fillers & .80 & .16 & .02 & .04 & .06 & .10 & .12 & .10 \\
\hline Related fillers & .79 & .16 & .02 & .05 & .07 & .11 & .12 & .11 \\
\hline
\end{tabular}

$\left[F(2,70)=1.35, M S_{\mathrm{e}}=0.003\right.$, n.s. $]$ and item errors $\left[F(2,70)=1.79, M S_{\mathrm{e}}=0.01\right.$, n.s. $]$. The latter two findings were consistent with Friedman tests [both $\chi^{2}(2, N=$ $46)<1.97$, n.s.]. Specific comparisons for Block 1 intrusions revealed a trend identical to that in Experiment 1; the greatest number of intrusions occurred with related fillers, followed by unrelated fillers, and the control condition [all $t \mathrm{~s}(35)>2.57, p \mathrm{~s}<.05]$. The Wilcoxon test $(Z=2.33$, $p<.05)$ confirmed these findings, with 19 participants showing more Block 1 intrusions in the related than in the unrelated conditions, 7 with the opposite pattern, and 10 ties. These findings showed that related fillers increased the number of foils incorrectly recalled.

\section{Discussion}

The error patterns were clearly identical to the patterns observed in Experiment 1; there was evidence that when the foil context was semantically similar, the probability of recalling the foil, instead of the target, increased, relative to when the foil context comprised unrelated words. This pattern was found only with the rhyme retrieval cues that subsumed both the foil and the target, and not with the onset cues that subsumed only the target. These findings strongly suggest that there were PI effects, despite the lack of supporting trends from the recall accuracy measures.

Inspection of the recall accuracy trend with rhyme retrieval cues in Table 4 suggests that the pattern is similar to the trend observed with the same-category cues in Table 2; that is, there was decreased performance in the conditions in which interference was expected, relative to the control condition. This apparent effect may have been obscured by the lower recall rates of the onset cue conditions (relative to the accuracy rates in the analogous different-category cue conditions). One possibility could be due to the "naturalness" of the retrieval cue that was used. A rhyme is a familiar component of a syllable (cf. Ladefoged, 1993, p. 248), whereas the onset nucleus component is not. Therefore, the latter may be a relatively weaker cue than the former. A weak retrieval cue may inherently not provide high cue-target diagnosticity in terms of matching the cue dimension with the target. As a result, performance is generally weaker using these cues, even though they subsume only the target.

To examine this possibility, Experiment 2B was conducted, in which the roles of the rhyme and the onset retrieval cues were reversed. The onset cues now subsumed both the foils and the targets, whereas the rhyme cue subsumed only the target. If the onset cues are weak, we would not expect to find a pattern in which PI is evident when the cue subsumes the foil and the target, which would be similar to Experiment 1 or what seems to be the case for the rhyme cues in Experiment 2A.

\section{EXPERIMENT 2B}

Table 3 depicts the structure of the critical two-block trials, which was identical to that for Experiment 2A, except that the target $d u d$ now shared the same onset nucleus portion of the foil duck. The retrieval cues were either sounds like the beginning of done, subsuming the foil and the target, or rhymes with thud, subsuming only the target.

\section{Method}

Participants. Forty-six introductory psychology students participated for course credit. None had participated in the previous experiments.

Design, Materials, and Procedure. A set of new targets and rhyme and onset cues were created. The same foils and related fillers as those in Experiment 2A were used, except in a few cases indicated 
in the Appendix. The average log frequency for the six lists did not differ $\left[F(5,714)=2.00, M S_{\mathrm{e}}=0.49\right.$, n.s. $]$ and ranged from 1.89 to 2.11 (overall $M=1.97, S D=0.71$ ). The same design, counterbalancing methods, and procedures as those in the previous experiments were used.

\section{Results}

The average serial recall rate in the one-block trials was $.74(S D=.16)$. Two participants did not meet criterion, and subsequent analyses included 44 participants. Performance in the distractor task was very high $(M=.94$, $S D=.04)$. Recall performance is summarized in the bottom half of Table 4.

Recall analyses. The ANOVA on recall rate yielded no reliable cue $\times$ filler interaction or main effect of filler (both $F \mathrm{~s}<1$ ). The main effect of cue was significant $\left[F(1,43)=47.39, M S_{\mathrm{e}}=0.03, p<.001\right]$; overall performance with rhyme cues $(M=.80, S D=.14)$ was much better than that with onset cues $(M=.65, S D=.17)$. This supports our earlier speculation that onset cues would yield generally poorer performance, because the participants might find the onset nucleus portion of a word less "natural" than the rhyme portion.

Error analyses. An error $\times$ cue $\times$ filler interaction was observed $\left[F(4,172)=6.08, M S_{\mathrm{e}}=0.01, p<.001\right]$. As in the previous experiments, the error $\times$ filler simple interaction was significant for onset cue $[F(4,172)=10.87$, $\left.M S_{\mathrm{e}}=0.01, p<.001\right]$, but not for rhyme cue $(F<1)$. Within the onset cue conditions, the simple main effect of filler was significant for Block 1 intrusions $[F(2,86)=$ $\left.24.32, M S_{\mathrm{e}}=0.01, p<.001\right]$ and item errors $[F(2,86)=$ $\left.4.45, M S_{\mathrm{e}}=0.01, p<.05\right]$, but not for omissions $(F<1)$. Specific comparisons showed that the effect was due entirely to the fact that very few Block 1 intrusions were observed in the control condition, in comparison with the unrelated and related filler conditions [both $t \mathrm{~s}(43)>$ $6.48, p s<.001]$. The critical finding is that the number of Block 1 intrusions did not differ between unrelated and related conditions $(t<1)$. The Wilcoxon test $(Z=0.29$, n.s.) confirmed these findings, with 16 participants showing more Block 1 intrusions in the related than in the unrelated conditions, 14 with the opposite pattern and 14 ties. Hence, unlike in the two previous experiments, there was no evidence that related fillers increased the number of foils incorrectly recalled when onset cues subsuming the foil and the target were used. For item errors, there were more errors in the control condition than in the unrelated and related conditions [both $t \mathrm{~s}(43)>2.42, p \mathrm{~s}<.05$ ], with no difference between the latter two $(t<1)$. However, the Friedman test was not significant for omissions or for item errors [both $\chi^{2}(2, N=41)<5.46$, n.s.].

Clearly, overall performance using onset cues was poor, in comparison with the rhyme cues. Even in the control condition, where interference from foils did not exist, performance was significantly below that in the rhyme cue conditions. There was some indication that interference occurred with onset cues in the unrelated and related conditions, given that Block 1 intrusions were observed. However, the critical finding that differed from those in the previous two experiments was that the probability of recalling a foil did not significantly increase in the related filler conditions - suggesting that even if semantic similarity in the foil context strengthened the foil, the potential increased interference with the target did not materialize, on account of the weak onset retrieval cue.

\section{Combined Analyses of Experiments $2 A$ and 2B}

The reversal of the roles of the rhyme and onset cues in Experiments 2A and 2B afforded an opportunity to use rhyme cues to analyze the PI effects independently from the analysis of the effects when onset cues were used. For recall accuracy, it was not possible to do a straightforward threeway ANOVA with experiment as a between-subjects factor, because the interference and no-interference conditions used different types of cues in each experiment. Hence, separate two-way mixed design ANOVAs were performed independently for rhyme and onset cues, with cue subsuming the foil and the target (interference conditions) versus cue subsuming the target only (no-interference conditions) constituting the between-subjects factor and the three filler conditions constituting the within-subjects factor. The relevant mixed ANOVAs were also performed for the error analyses.

Rhyme cues. Figure 2 illustrates the pattern of results across the two experiments for rhyme cues. The ANOVA on recall rates yielded a significant interaction $[F(2,156)=$ $\left.3.43, M S_{\mathrm{e}}=0.02, p<.05\right]$. The source of the interaction was a significant simple main effect of filler when the cue subsumed the foil and the target [Experiment 2A; $\left.F(2,156)=6.15, M S_{\mathrm{e}}=0.02, p<.01\right]$, but not when the cue subsumed only the target (Experiment $2 \mathrm{~B} ; F<1$ ). When the cue subsumed the foil and the target, no recall differences were found between the unrelated and the related filler conditions $(F<1)$, but recall was worse for these two conditions than for the control condition [both $\left.F \mathrm{~s}(1,35)>8.28, M S_{e} \mathrm{~s}<0.03, p \mathrm{~s}<.01\right]$. This finding is identical to the recall rate results in Experiment 1 and, essentially, provides statistical support for our earlier observation in Experiment 2A that the pattern for the rhyming cues followed the same trend as that for the semantic cues in Experiment 1 but was obscured by the lower performance levels for the onset cues. The error analyses revealed a significant error $\times$ filler $\times$ interference/no-interference interaction $\left[F(4,312)=7.43, M S_{\mathrm{e}}=0.01, p<.001\right]$. Follow-up analyses were identical to those reported in Experiments $2 \mathrm{~A}$ and $2 \mathrm{~B}$ and will not be repeated here.

Onset cues. Figure 3 illustrates the pattern of results across the two experiments for onset cues. No reliable effects were found from the ANOVA on recall rates (all $F \mathrm{~s}<2.91, M S_{e} \mathrm{~s}<0.09$, n.s.). The error analyses revealed a significant error $\times$ filler $\times$ interference/no-interference interaction $\left[F(4,312)=6.06, M S_{\mathrm{e}}=0.01, p<.001\right]$. Again, follow-up analyses were identical to those reported in Experiments $2 \mathrm{~A}$ and $2 \mathrm{~B}$ and will not be repeated here.

To summarize, the independent analyses of rhyme and onset cue effects revealed that using rhyme cues resulted in a pattern of results that was identical to that using semantic cues in Experiment 1. Hence, PI effects caused by using a cue that subsumed the foil and the target increased 


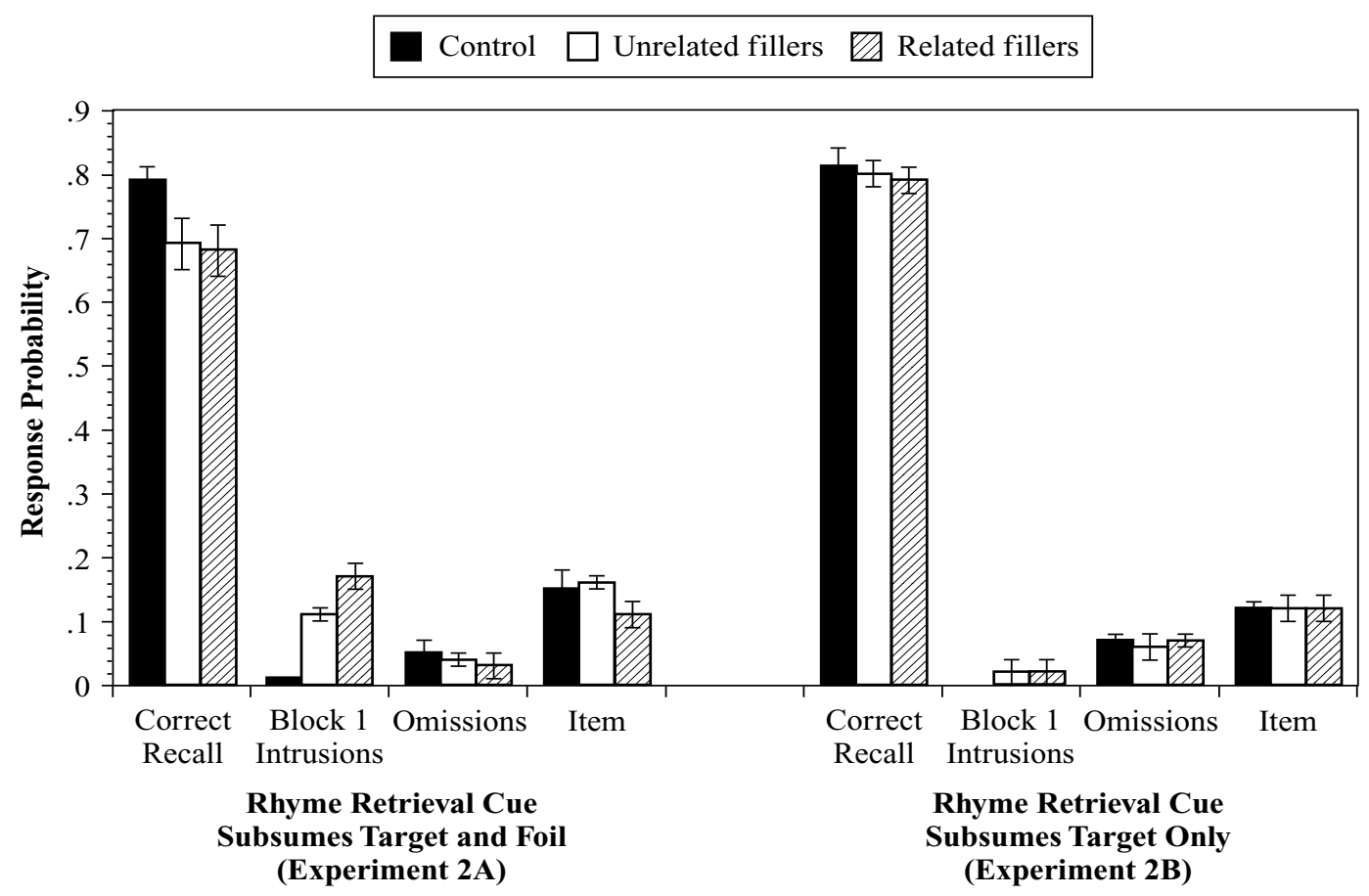

Figure 2. Average response probability $(+S E s)$ of recall and error measures across filler conditions, using rhyme retrieval cues.

when the foil block comprised words with a contextual organization. This finding can be generalized across semantic and rhyme cues and contextual similarity on the basis of these factors. No evidence of this effect was found for onset cues, which may be attributed to the potentially weak diagnosticity and familiarity with onset cues.

\section{Discussion}

The results of the previous experiments are consistent with the prediction that contextual organization strengthens the foil, rather than weakens it. This resulted in increased foil intrusions when the cue subsumed both the foil and the target, but not when the cue subsumed only the target. Despite a strengthened foil in the rhyming and related filler conditions, there was no effect when the cue uniquely pointed to the target, as evidenced by the lack of differential performance levels among the filler conditions when the cue subsumed only the target. This strongly suggests that PI is driven first and foremost by the nature of the retrieval cue, regardless of the surrounding context. The context may strengthen foil activation under certain conditions, but the effects of this strengthening can be manifested only when a retrieval cue points to both the foil and the target. This empirical finding is consistent with the view that STM recall is a cue-driven process.

Of course, one could argue that the recall accuracy findings are not consistent with the conclusion that contextual organization strengthens the foil. There was no differential performance in recall accuracy between the interference conditions with or without contextual organization, although the pattern of Block 1 intrusions critically suggests that dif- ferential PI effects were evident. Nevertheless, some independent index that the participants encoded the contextual organization would lend greater weight to the conclusion.

For this, we compared the average serial recall performance between the 10 trials in the one-block conditions that either rhymed (Experiment 1) or were semantically related (Experiments $2 \mathrm{~A}$ and $2 \mathrm{~B}$ ) with the corresponding 20 trials that did not rhyme or were unrelated. For Experiment 1 , no differences were found between the rhyme $(M=.69, S D=.17)$ and the nonrhyme $(M=.70, S D=$ $.16)$ trials $(t<1)$. For Experiments $2 \mathrm{~A}[t(35)=2.11, p<$ $.05]$ and $2 \mathrm{~B}[t(44)=7.84, p<.001]$, the participants reliably recalled more words in the semantically related trials $(M \mathrm{~s}=.78$ and $.83, S D \mathrm{~s}=.12$ and .14 , for Experiments $2 \mathrm{~A}$ and $2 \mathrm{~B}$, respectively) than in the unrelated trials $(M \mathrm{~s}=$ .73 and $.71, S D \mathrm{~s}=.15$ and .15 ).

These results suggest that for the latter two experiments, there is unequivocal evidence that the participants encoded the semantic similarity in the contextually organized foil blocks, and the findings are similar to those in previous work showing a semantic similarity advantage in serial recall (e.g., Poirier \& Saint-Aubin, 1995). The findings for Experiment 1 were surprising, since evidence of a phonological similarity effect was expected. Although this may suggest that the participants did not encode the rhyme organization, this view would be problematic in explaining how rhyme organization would result in increased Block 1 intrusion errors if the participants did not encode the rhyme.

We attempted to resolve this indirectly by replicating Experiment 1 in the next experiment, but this time, the rhyming fillers were placed in the target block, instead of 


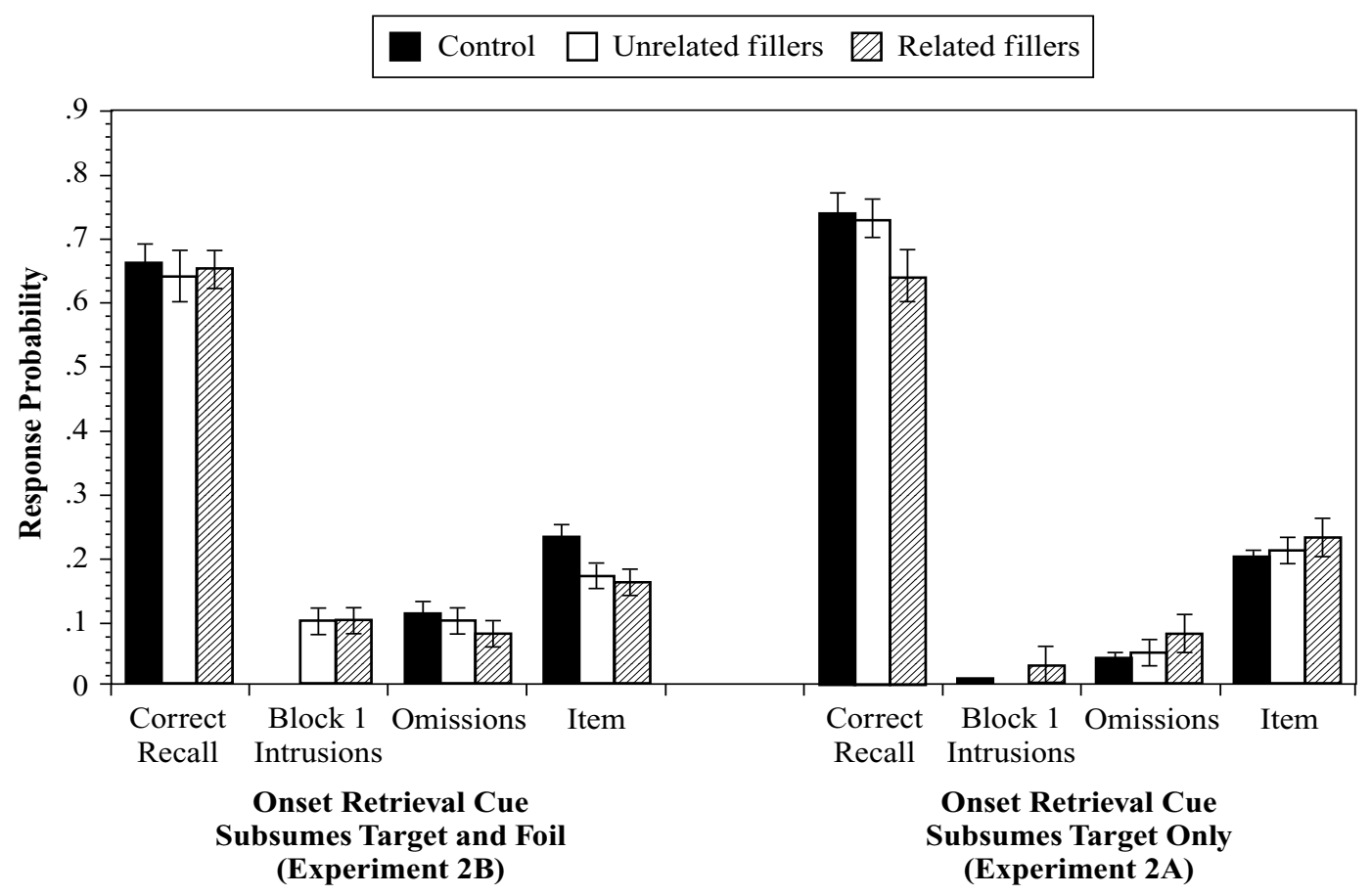

Figure 3. Average response probability $(+S E s)$ of recall and error measures across filler conditions, using onset nucleus retrieval cues.

the foil block. This is essentially the manipulation used in Tehan and Humphreys (1998), although they used only one rhyming filler for their rhyme experiment. By having the rhymes in the second block, there would be no contextual organization in the first block, including the single-block filler trials (this was to ensure that the participants could not predict one- and two-block trials in advance). Although this made it impossible to have a similar independent index of whether the participants encoded contextual organization, the rationale was that if the results implicating foil strengthening were replicated in this experiment, it would strongly suggest that contextual organization influences PI, because there would now be converging evidence that context effects occur across two different contextual block manipulations.

Another motivation for the next experiment was that Tehan and Humphreys (1998) did not include conditions in which the retrieval cue was from a different semantic category than was the foil. As was noted above, if foils strengthened by a rhyme context have no effect when the retrieval cue subsumes only the target, there would be very strong evidence that the retrieval cue was driving PI.

\section{EXPERIMENT 3}

\section{Method}

Participants. Thirty-seven introductory psychology students participated for course credit. None had participated in the previous experiments.

Design, Materials, and Procedure. The design, materials, and procedure were identical to those in Experiment 1, except that the three rhyming fillers in the foil block were now switched to the target block and the unrelated fillers in the corresponding target block were switched to the foil block. Using the example presented in Table 1 for Experiment 1, the rhyming condition in Experiment 3 comprised " $x$, shoe, $x, x$ " in Block 1 and "loo, boot, flu, zoo" in Block 2. All the one-block trials comprised unrelated words.

\section{Results and Discussion}

The average serial recall rate in the one-block trials was $.68(S D=.20)$. Two participants did not meet criterion, and subsequent analyses included the scores from 35 participants. Distractor task performance was very high $(M=.95$, $S D=.03$ ). Recall performance is summarized in Table 5 .

Recall analyses. A significant interaction was obtained for recall rate $\left[F(2,68)=7.11, M S_{\mathrm{e}}=0.01, p<.01\right]$. The simple main effect of filler was significant for samecategory cues $\left[F(2,68)=7.14, M S_{\mathrm{e}}=0.01, p<.01\right]$, but not for different-category cues $\left[F(2,68)=1.21, M S_{\mathrm{e}}=\right.$ 0.01 , n.s.]. With same-category cues, no reliable difference was observed between the rhyming and the nonrhyming filler conditions $\left[F(1,34)=2.03, M S_{\mathrm{e}}=0.02\right.$, n.s.], but recall was worse for these two conditions than for the control condition [both $F \mathrm{~s}(1,34)>6.26, M S_{e} \mathrm{~s}<0.02$, $p \mathrm{~s}<.05]$. This finding is identical to the recall accuracy results in Experiment 1; recall accuracy decreased only when the semantic retrieval cue subsumed the foil and the target, and there was no reliable difference in accuracy between target blocks that had fillers rhyming with the foil and those with nonrhyming fillers.

Error analyses. An error $\times$ cue $\times$ filler interaction was observed $\left[F(4,136)=10.67, M S_{\mathrm{e}}=0.01, p<.001\right]$. 
Table 5

Mean Correct Recall and Error Rates in Experiment 3

\begin{tabular}{|c|c|c|c|c|c|c|c|c|}
\hline \multirow[b]{3}{*}{ Condition } & & & \multicolumn{6}{|c|}{ Type of Error } \\
\hline & \multicolumn{2}{|c|}{ Recall } & \multicolumn{2}{|c|}{$\begin{array}{c}\text { Block 1 } \\
\text { Intrusions }\end{array}$} & \multicolumn{2}{|c|}{ Omissions } & \multicolumn{2}{|c|}{ Item } \\
\hline & $M$ & $S D$ & $M$ & $S D$ & $M$ & $S D$ & $M$ & $S D$ \\
\hline \multicolumn{9}{|l|}{ Same-category retrieval cue } \\
\hline Control (no interference) & .80 & .17 & .00 & .02 & .08 & .10 & .12 & .14 \\
\hline Nonrhyming fillers & .74 & .21 & .07 & .10 & .07 & .11 & .11 & .12 \\
\hline Rhyming fillers & .69 & .20 & .20 & .16 & .04 & .07 & .07 & .08 \\
\hline \multicolumn{9}{|l|}{ Different-category retrieval cue } \\
\hline Control (no interference) & .82 & .17 & .00 & .00 & .09 & .11 & .09 & .09 \\
\hline Nonrhyming fillers & .85 & .14 & .00 & .02 & .05 & .07 & .10 & .10 \\
\hline Rhyming fillers & .85 & .16 & .01 & .04 & .05 & .08 & .08 & .10 \\
\hline
\end{tabular}

The error $\times$ filler simple interaction was significant for same-category cues $\left[F(4,136)=15.67, M S_{\mathrm{e}}=0.01, p<\right.$ $.001]$. The simple main effect of filler was significant for Block 1 intrusions $\left[F(2,68)=32.51, M S_{\mathrm{e}}=0.01, p<\right.$ $.001]$, but not for omissions $\left[F(2,68)=2.69, M S_{\mathrm{e}}=0.01\right.$, n.s.] and item errors $\left[F(2,68)=2.59, M S_{\mathrm{e}}=0.01\right.$, n.s. $]$. The latter two findings were consistent with Friedman tests [both $\chi^{2}(2, N=35)<3.78$, n.s.]. Specific comparisons for Block 1 intrusions revealed a trend identical to that in Experiment 1; the greatest number of intrusions occurred with related fillers, followed by unrelated fillers and the control condition [all $t \mathrm{~s}(34)>4.27, p \mathrm{~s}<.001$ ]. The Wilcoxon test $(Z=3.66, p<.001)$ confirmed these findings, with 22 participants showing more Block 1 intrusions in the rhyming than in the nonrhyming conditions, 4 with the opposite pattern, and 9 ties. These findings showed that rhyming fillers increased the number of foils incorrectly recalled when the cue subsumed both the foil and the target.

Unlike in Experiment 1, the error $\times$ filler simple interaction was significant for different-category cues $\left[F(4,136)=3.98, M S_{\mathrm{e}}=0.003, p<.01\right]$. This was due to a significant simple main effect of filler for omissions $\left[F(2,68)=6.68, M S_{\mathrm{e}}=0.004, p<.01\right]$, but not for Block 1 intrusions $\left[F(2,68)=1.91, M S_{\mathrm{e}}=0.001\right.$, n.s. $]$ or for item errors $(F<1)$. Friedman tests confirmed the findings for omissions $\left[\chi^{2}(2, N=35)=9.11, p<.05\right]$ and item errors $\left[\chi^{2}(2, N=35)=0.61\right.$, n.s.]. Additional tests for omissions showed that there were more errors in the control condition [both $t \mathrm{~s}(34)>2.84, p \mathrm{~s}<.01$ ] than in the other two filler conditions, which did not differ $(t<1)$. We have no explanation for this finding, but the important thing to note is that there is no evidence of any differences between the critical nonrhyming and rhyming filler conditions. This implies that whatever the cause of the increased level of omissions in the control condition, having rhyming fillers did not result in differential error rates when the retrieval cue subsumed only the target.

\section{GENERAL DISCUSSION}

The present study explored the extent to which susceptibility to PI in the cued recall task of Tehan and Humphreys $(1995,1996)$ can be influenced by contextual or organiza- tional information in the foil block. We introduced a novel manipulation in which the words in the to-be-forgotten block shared similar phonological attributes in Experiment 1 and similar semantic attributes in Experiments 2A and $2 \mathrm{~B}$. We considered two opposing predictions. First, item similarity along one dimension would reduce the level of PI when a retrieval cue subsuming both the foil and the target, but emphasizing a different dimension, was used. A foil studied in a particular contextual organization may inhibit links to attributes of the word that are irrelevant to the context. As such, when a retrieval cue incompatible with the context is used, the probability that the foil would be recalled, instead of the target, is attenuated. Second, studying a foil in context would strengthen, rather than weaken, the foil's activation. The contextual information would increase the activation of the foil on the basis of the shared features. As such, even when a retrieval cue that subsumed the foil on other dimensions was used, the highly activated foil would increase the probability that it would be recalled, instead of the target.

In all the experiments, the evidence strongly supports the second hypothesis. PI was evident when the cue subsumed both the foil and the target. Although there were no differences in recall accuracy between conditions in which contextual organization was present or absent, reliable increases in foil intrusions were observed when contextual organization was present. This finding was generalized across rhyme contexts with semantic cues and semantic contexts with rhyme cues. It was further generalized to rhyme contexts in the target block, a result that replicated the basic findings from Tehan and Humphreys (1998). The pattern of results is consistent with the interpretation that contextual information matching the foil would strengthen, rather than weaken, its ability to cause PI.

In terms of the roles of encoding and retrieval processes in PI, the failure to find that PI does not vary with contextual organization does not allow us to conclude unequivocally that PI is due to retrieval processes alone. However, although encoding appears to play a role, the pattern of results still favors a retrieval locus, for the following reasons. The fact that Block 1 intrusions varied with context suggests that the encoding context is also important in influencing the degree of PI observed. If the strength of the foil is boosted by the contextual information, its efficacy 
in interfering with recall of the target will increase. However, the effect of encoding context was manifested if and only if the retrieval cue subsumed the foil, as well as the target. When the cue subsumed a dimension that encompassed only the target, but not the foil, it did not matter whether the foil was strengthened by the context or not; no PI was evident. Hence, the precise locus of encoding processes is, perhaps, limited to influencing the potential for interference, whereas the actual manifestation of PI depends on the nature of the retrieval cue. This strongly suggests that retrieval in STM is a cue-driven process. This account is consistent with previous interpretations regarding the retrieval locus of PI effects in STM cued recall (Tehan \& Humphreys, 1996) and release from PI paradigms (Gardiner et al., 1972).

One potential qualification to the conclusions of this study is the inconclusive findings with regard to the use of onset nucleus cues that complicated the interpretation of Experiments $2 \mathrm{~A}$ and $2 \mathrm{~B}$. The results suggest that these cues were relatively weak and unfamiliar to the participants, since recall was relatively poor even in conditions in which no interference was expected. However, there did seem to be some Block 1 intrusions when the onset cue subsumed the foil and the target, although there was no increase in these intrusions when the foil was studied in the context of semantically similar fillers, unlike in the case with rhyme cues and the analogous conditions with semantic cues.

Because similar effects were observed across manipulations involving rhyme and semantic attributes, the results suggest that these word features are simultaneously active during retrieval (cf. Tehan \& Humphreys, 1998). In addition to the research cited in the introduction regarding the contribution of LTM factors to STM performance, researchers have found that using articulatory suppression to disrupt articulatory or phonological coding, which generally forms the basis of rehearsal mechanisms in the standard models of STM, tends to enhance the effects of other word attributes in recall. For example, Saint-Aubin and Poirier (1999) and Poirier and Saint-Aubin (1995) demonstrated that the magnitude of the semantic similarity advantage in serial recall tends to be greater when articulatory rehearsal is suppressed. This suggests that disruption or impairment of one form of coding tends to enhance the use of other codes. This argument has received support from studies showing double dissociations among patients with selective impairment to semantic or phonological memory, in which they performed normally for memory tasks that emphasized the dimension that was unimpaired, but poorly for those involving the impaired dimension (e.g., Martin \& Romani, 1994; Martin, Shelton, \& Yaffee, 1994), or in which patients showed increased phonological errors when semantics was impaired (e.g., Caza, Belleville, \& Gilbert, 2002). Indeed, the redintegration model of STM recall (Schweickert, 1993) suggests that when memory traces are degraded, word attributes derived from LTM, such as semantics and phonotactic structure (Gathercole et al., 1999), can be brought to bear in recovering the memory traces for successful recall. Taken together, these findings are consistent with the view that separate levels of representations of word features, such as phonology and semantics, are simultaneously available during STM recall.

In summary, the present results extend Tehan and Humphreys's $(1995,1996,1998)$ work, using their STM cued recall paradigm. We have demonstrated that their earlier results showing cue-driven recall were replicated when we introduced a novel manipulation involving the foil context, and the results were generalized across both rhyming and semantic cues and contexts. Encoding contextual organization strengthens the foil, rather than weakens it - presumably, by an increased activation in the foil, due to activation of shared features among the contextual fillers. This increased activation increases the potential for interfering with the target during recall, but the increased PI will be manifested only if the retrieval cue's attributes subsume both the foil and the target. The increased interference potential is not realized if the cue subsumes only the target.

Taken together, these findings support the assertion that recall in STM is a cue-driven process (Nairne, 2002b). The present experimental design certainly does not rule out, nor is it intended to test, the "standard model" of STM that emphasizes rehearsal and time-based processes (e.g., Baddeley, 2000; Baddeley \& Hitch, 1974). Rather, it adds to the growing evidence that the nature of retrieval cues and the conditions that affect cue-target diagnosticity are important factors to consider in explaining recall in STM.

\section{REFERENCES}

Baddeley, A. D. (2000). The episodic buffer: A new component of working memory? Trends in Cognitive Sciences, 4, 417-423.

Baddeley, A. D., \& Hitch, G. J. (1974). Working memory. In G. H. Bower (Ed.), The psychology of learning and motivation (Vol. 8, pp. 47-89). New York: Academic Press.

Battig, W. F., \& Montague, W. E. (1969). Category norms for verbal items in 56 categories: A replication and extension of the Connecticut category norms. Journal of Experimental Psychology Monographs, 80 (Pt.2), 1-46.

Bourassa, D. C., \& Besner, D. (1994). Beyond the articulatory loop: A semantic contribution to serial order recall of subspan lists. Psychonomic Bulletin \& Review, 1, 122-125.

Caza, N., Belleville, S., \& Gilbert, B. (2002). How loss of meaning with preservation of phonological word form affects immediate serial recall performance: A linguistic account. NeuroCase, 8, 255-273.

Conrad, R., \& Hull, A. J. (1964). Information, acoustic confusion, and memory span. British Journal of Psychology, 55, 429-432.

Dillon, R. F., \& BitTner, L. A. (1975). Analysis of retrieval cues and release from proactive inhibition. Journal of Verbal Learning \& Verbal Behavior, 14, 616-622.

Fallon, A. B., Groves, K., \& Tehan, G. (1999). Phonological similarity and trace degradation in the serial recall task: When CAT helps RAT, but not MAN. International Journal of Psychology, 34, 301-307.

Gardiner, J. M., Craik, F. I. M., \& Birtwistle, J. (1972). Retrieval cues and release from proactive inhibition. Journal of Verbal Learning \& Verbal Behavior, 11, 778-783.

Gathercole, S. E., Frankish, C. R., Pickering, S. J., \& Peaker, S. (1999). Phonotactic influences on short-term memory. Journal of Experimental Psychology: Learning, Memory, \& Cognition, 25, 84-95.

GoH, W. D., \& Pisoni, D. B. (2003). Effects of lexical competition on immediate memory span for spoken words. Quarterly Journal of Experimental Psychology, 56A, 929-954. 
Hulme, C., Maughan, S., \& Brown, G. D. A. (1991). Memory for familiar and unfamiliar words: Evidence for a long-term memory contribution to short-term memory span. Journal of Memory \& Language, 30, 685-701.

Hulme, C., Roodenrys, S., Schweickert, R., Brown, G. D. A., Martin, S., \& Stuart, G. (1997). Word-frequency effects on shortterm memory tasks: Evidence for a redintegration process in immediate serial recall. Journal of Experimental Psychology: Learning, Memory, \& Cognition, 23, 1217-1232.

KučERA, H., \& FrANCIS, W. N. (1967). Computational analysis of presentday American English. Providence, RI: Brown University Press.

LADEFoged, P. (1993). A course in phonetics (3rd ed.). Fort Worth: Harcourt Brace Jovanovich.

Martin, R. C., \& Romani, C. (1994). Verbal working memory and sentence comprehension: A multiple-components view. Neuropsychology, 8, 506-523.

Martin, R. C., Shelton, J. R., \& Yaffee, L. S. (1994). Language processing and working memory: Neuropsychological evidence for separate phonological and semantic capacities. Journal of Memory \& Language, 33, 83-111.

McEvoy, C. L., \& Nelson, D. L. (1982). Category name and instance norms for 106 categories of various sizes. American Journal of Psychology, 95, 581-634.

McGeoch, J. A. (1932). Forgetting and the law of disuse. Psychological Review, 39, 352-370.

NAIRne, J. S. (1990). A feature model of immediate memory. Memory \& Cognition, 18, 251-269.

NaIRne, J. S. (2002a). The myth of the encoding-retrieval match. Memory, 10, 389-395.

NAIRNE, J. S. (2002b). Remembering over the short-term: The case against the standard model. Annual Review of Psychology, 53, 53-81.

NaIRne, J. S., \& Kelley, M. R. (1999). Reversing the phonological similarity effect. Memory \& Cognition, 27, 45-53.

NAIRne, J. S., \& Neumann, C. (1993). Enhancing effects of similarity on long-term memory for order. Journal of Experimental Psychology: Learning, Memory, \& Cognition, 19, 329-337.

Nelson, D. L., Bennett, D. J., Gee, N. R., Schreiber, T. A., \& MCKINNEY, V. M. (1993). Implicit memory: Effects of network size and interconnectivity on cued recall. Journal of Experimental Psy- chology: Learning, Memory, \& Cognition, 19, 747-764.

Nelson, D. L., McEvoy, C. L., \& Schreiber, T. A. (1998). The University of South Florida word association, rhyme, and word fragment norms. Available at w3.usf.edu/FreeAssociation/Intro.html.

Nelson, D. L., McKinney, V. M., Gee, N. R., \& Janczura, G. A. (1998). Interpreting the influence of implicitly activated memories on recall and recognition. Psychological Review, 105, 299-324.

Nelson, D. L., Walling, J., \& McEvoy, C. L. (1979). Doubts about depth. Journal of Experimental Psychology: Human Learning \& Memory, 5, 24-44.

Poirier, M., \& Saint-Aubin, J. (1995). Memory for related and unrelated words: Further evidence on the influence of semantic factors in immediate serial recall. Quarterly Journal of Experimental Psychology, 48A, 384-404.

Roodenrys, S., Hulme, C., Lethbridge, A., Hinton, M., \& Nimmo, L. M. (2002). Word-frequency and phonological-neighborhood effects on verbal short-term memory. Journal of Experimental Psychology: Learning, Memory, \& Cognition, 28, 1019-1034.

RoODEnRYs, S., \& Quinlan, P. T. (2000). The effects of stimulus set size and word frequency on verbal serial recall. Memory, 8, 71-78.

SaINT-Aubin, J., \& PoIrIER, M. (1999). Semantic similarity and immediate serial recall: Is there a detrimental effect on order information? Quarterly Journal of Experimental Psychology, 52A, 367-394.

SCHWEICKERT, R. (1993). A multinomial processing tree model for degradation and redintegration in immediate recall. Memory \& Cognition, 21, 168-175

Tehan, G., \& Humphreys, M. S. (1995). Transient phonemic codes and immunity to proactive interference. Memory \& Cognition, 23, 181-191.

Tehan, G., \& Humphreys, M. S. (1996). Cuing effects in short-term recall. Memory \& Cognition, 24, 719-732.

Tehan, G., \& Humphreys, M. S. (1998). Creating proactive interference in immediate recall: Building a DOG from a DART, a MOP, and a FIG. Memory \& Cognition, 26, 477-489.

Walker, I., \& Hulme, C. (1999). Concrete words are easier to recall than abstract words: Evidence for a semantic contribution to shortterm serial recall. Journal of Experimental Psychology: Learning, Memory, \& Cognition, 25, 1256-1271.

WiCKEns, D. D. (1970). Encoding categories of words: An empirical approach to meaning. Psychological Review, 77, 1-15. 
APPENDIX

Critical Words and Retrieval Cues Across Word Lists

Table A1

Experiments 1 and 3

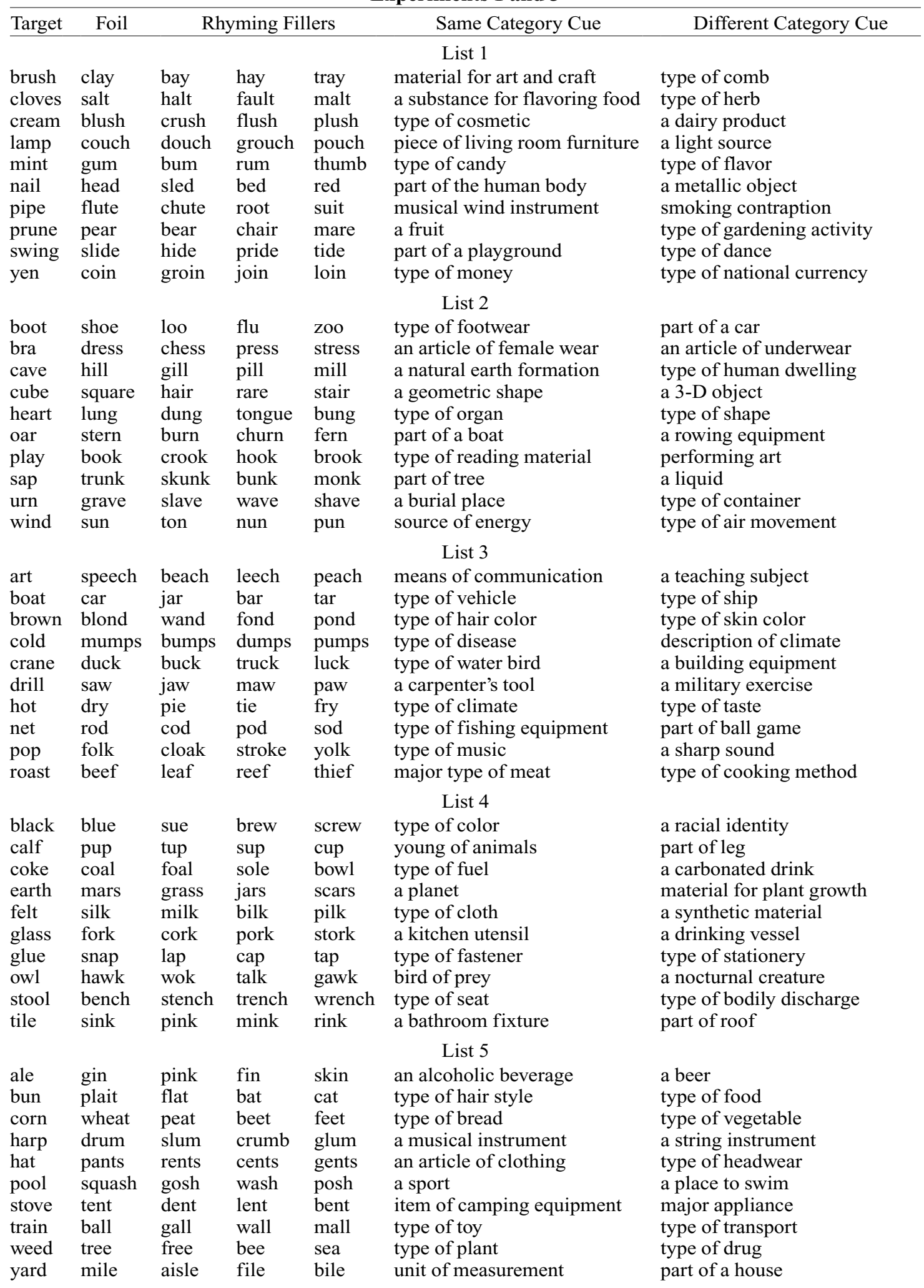


APPENDIX (Continued)

\begin{tabular}{|c|c|c|c|c|c|c|}
\hline \multicolumn{7}{|c|}{ Table A1 (Continued) } \\
\hline Target & Foil & \multicolumn{3}{|c|}{ Rhyming Fillers } & Same Category Cue & Different Category Cue \\
\hline \multicolumn{7}{|c|}{ List 6} \\
\hline axe & gun & fun & stun & run & a weapon & type of fire-fighting equipment \\
\hline bank & house & spouse & mouse & louse & type of building & part of a river \\
\hline brass & steel & heel & wheel & seal & type of metal & type of band \\
\hline chalk & pen & fan & den & hen & writing implement & a powdery substance \\
\hline mole & rat & jet & bet & mat & a rodent & a facial marking \\
\hline palm & pine & spine & wine & vine & type of tree & part of hand \\
\hline punch & tea & ski & bee & pea & a nonalcoholic beverage & an act of violence \\
\hline sand & wood & mood & hood & good & building material & part of a beach \\
\hline vault & sprint & flint & glint & hint & a track and field event & type of room \\
\hline watch & ring & king & string & wing & type of accessory & type of timepiece \\
\hline
\end{tabular}

Table A2

Experiments 2A and 2B

\begin{tabular}{|c|c|c|c|c|c|c|c|c|c|}
\hline \multicolumn{2}{|c|}{ Target } & \multicolumn{2}{|c|}{$\begin{array}{c}\text { Rhyme Cue } \\
\text { (Rhymes With }\end{array}$} & \multicolumn{2}{|c|}{$\begin{array}{l}\text { Onset Nucleus Cue } \\
\text { (Sounds Like the } \\
\text { Beginning of }\end{array}$} & \multicolumn{4}{|c|}{ Both $2 \mathrm{~A}$ and $2 \mathrm{~B}$} \\
\hline $2 \mathrm{~A}$ & 2B & $2 \mathrm{~A}$ & 2B & $2 \mathrm{~A}$ & 2B & Foil & Semant & llly Rela & Fillers \\
\hline \multicolumn{10}{|c|}{ List 1} \\
\hline bed & hen & dead & ten & bet & hell & head & leg & nose & toe \\
\hline bumps & mug & humps & tug & bust & much & mumps & cold & flu & stroke \\
\hline & snatch & cap & batch & land & snack & snap & glue & hook & pin \\
\hline maze & hale & gaze & pale & maim & hate & haze & dust & smog & smoke \\
\hline scars & mart & jars & cart & scarf & march & mars & earth & star & sun \\
\hline skin & gym & win & him & skip & jig & gin & beer & scotch & wine \\
\hline thumb & gush & rum & hush & thug & gut & gum & fudge & $\operatorname{mint}$ & sweet \\
\hline tight & sign & bright & line & type & side & sight & smell & taste & touch \\
\hline vine & pipe & spine & type & vibe & pike & pine & birch & oak & palm \\
\hline wheel & steep & heel & sleep & wheeze & steam & steel & bronze & tin & zinc \\
\hline \multicolumn{10}{|c|}{ List 2} \\
\hline bee & tease & pea & please & bean & teeth & tea & juice & punch & shake \\
\hline brain & rail & pain & fail & brake & rate & rain & hot & snow & storm \\
\hline cork & fawn & stork & gone & corpse & form & fork & pan & pot & spoon \\
\hline cup & pun & sup & fun & cult & putt & pup & calf & chick & foal \\
\hline fawn & shed & dawn & fed & false & chef & prawn* & clam & crab & squid \\
\hline feet & weave & beat & leave & fee & week & wheat & corn & loaf & rye \\
\hline monk & truss & skunk & fuss & month & trudge & trunk & branch & root & sap \\
\hline park & bard & dark & hard & parch & barn & bark & chirp & purr & roar \\
\hline pond & blotch & fond & notch & pomp & block & blond & black & brown & red \\
\hline $\operatorname{tar}$ & carve & bar & starve & $\operatorname{tart}$ & calm & car & boat & bus & truck \\
\hline \multicolumn{10}{|c|}{ List 3} \\
\hline bat & plaid & cat & maid & back & plan & plait & bun & fringe & perm \\
\hline brook & bull & crook & pull & brood & butch & book & play & poem & text \\
\hline buck & dud & luck & thud & butt & done & duck & crane & stork & swan \\
\hline burn & marsh & fern & harsh & burp & mark & stern* & bow & oar & sail \\
\hline dent & tech & bent & peck & deaf & tell & tent & camp & match & stove \\
\hline fault & sawn & halt & lawn & fog & sort & salt & cloves & sauce $^{\dagger}$ & thyme \\
\hline lark & shard & mark & lard & lard & sharp & shark & bass & eel & trout \\
\hline leaf & beep & reef & leap & leash & beach & beef & ham & pork & roast \\
\hline rare & cute & stair & mute & rent & cue & square* & cube $^{\dagger}$ & round & sphere \\
\hline trench & bell & wrench & fell & trek & bet & bench & chair & couch & stool \\
\hline
\end{tabular}


APPENDIX (Continued)

\begin{tabular}{|c|c|c|c|c|c|c|c|c|c|}
\hline \multicolumn{10}{|c|}{ Table A2 (Continued) } \\
\hline \multicolumn{10}{|c|}{$\begin{array}{l}\text { Onset Nucleus Cue } \\
\text { (Sounds Like the } \\
\text { Beginning of }\end{array}$} \\
\hline $2 \mathrm{~A}$ & $2 \mathrm{~B}$ & $2 \mathrm{~A}$ & $2 \mathrm{~B}$ & $2 \mathrm{~A}$ & 2B & Foil & Semant & lly Relat & Fillers \\
\hline \multicolumn{10}{|c|}{ List 4} \\
\hline foal & cove & goal & grove & foam & coat & coal & gas & oil & wind \\
\hline joke & foam & yolk & home & jolt & phone & folk & blues & jazz & pop \\
\hline pail & tame & rail & same & paint & take & tail & fin & gill & scale \\
\hline paw & source & law & horse & pause & sought & saw & drill & file & nail \\
\hline pill & hiss & bill & miss & pit & hit & hill & cliff & lake & rock \\
\hline pink & $\operatorname{sip}$ & rink & lip & pig & $\sin$ & sink & tap & tile & tub \\
\hline pod & rot & nod & lot & pox & wrong & $\operatorname{rod}$ & bait & fish & net \\
\hline run & gust & stun & lust & rush & gulf & gun & axe & knife & sword \\
\hline spouse & howl & louse & fowl & spout & hound & house & bank & court & school \\
\hline wok & horde & talk & ford & ward & hall & hawk & dove & gull & jay \\
\hline \multicolumn{10}{|c|}{ List 5} \\
\hline bet & vest & pet & best & bell & vent & vet & clerk & judge & nurse \\
\hline bile & mine & style & dine & bike & might & mile & foot & inch & yard \\
\hline chess & drench & stress & wrench & check & dread & dress & blouse & pants & shirt \\
\hline & rash & mat & hash & fan & ran & rat & mole & mouse & shrew \\
\hline flush & bluff & plush & puff & flux & blood & blush & base & cream & rouge \\
\hline glint & sprig & flint & fig & glib & spring & sprint & jump & throw & vault \\
\hline loo & booze & flu & lose & loom & boom & shoe* & boot $^{\dagger}$ & clog & heels \\
\hline mall & balk & fall & talk & moss & board & ball & doll & kite & top \\
\hline plea & fleece & glee & lease & pleat & fleet & flea & ant & fly & wasp \\
\hline slave & graze & wave & maze & slay & great & grave & crypt & tomb & urn \\
\hline \multicolumn{10}{|c|}{ List 6} \\
\hline good & brim & food & slim & goose & bridge & wood* & brick $^{\dagger}$ & mud & stone \\
\hline hair & grate & bear & late & hem & grace & pear* & grape $^{\dagger}$ & lime & plum \\
\hline hen & peg & ten & beg & hell & pet & pen & brush & chalk & quill \\
\hline join & coil & groin & boil & joint & coif & coin & franc & pound & yen \\
\hline king & rim & sing & $\operatorname{limb}$ & kiss & rich & ring & scarf & tie & watch \\
\hline milk & sill & bilk & pill & mill & sit & silk & felt & fur & wool \\
\hline pest & neck & best & wreck & pence & knelt & nest & cage & den & sty \\
\hline posh & squat & quash & swat & pomp & squad & squash & golf & pool & ski \\
\hline sea & heck & free & deck & seek & helm & tree* & bush & hedge $^{\dagger}$ & weed \\
\hline slum & drug & crumb & bug & slug & drunk & drum & flute & harp & horn \\
\hline
\end{tabular}

(Manuscript received August 4, 2004;

revision accepted for publication June 1, 2005.) 